\title{
Distance Education during COVID-19 Pandemic: The Perceptions and Preference of University Students in Malaysia Towards Online Learning
}

\author{
Husna Hafiza Razami ${ }^{1}$, Roslina Ibrahim ${ }^{2}$ \\ UTMSPACE, Kuala Lumpur, Malaysia ${ }^{1}$ \\ Razak Faculty of Technology and Informatics, Universiti Teknologi Malaysia, Kuala Lumpur, Malaysia ${ }^{2}$
}

\begin{abstract}
The sudden shift from the brick-and-mortar approach to online distance learning due to the coronavirus pandemic greatly impacted everyone involved, particularly students. Hence, it is critical to identify the perception of students regarding the challenges they faced, their satisfaction with remote learning, as well as their preferences and recommendations for improvement which are the objectives of this research. A survey taken by $\mathbf{4 0 8}$ diploma students with 377 valid answers for the quantitative study showed that the most common difficulties they encountered were in terms of interaction, concentration and motivation. The mean of the perceived challenges was found to be significantly different depending on the respondents' prior e-learning experience and area of residence. With regard to the relevant activities to be conducted virtually, most participants approved of assessments such as quiz, assignments and tests. Animation and gamification received the highest votes as the elements that students wished were incorporated to boost their online learning engagement. The findings from this research contribute to existing studies on the perceptions and preference of students towards distance education by shedding light on the perspective of diploma students.
\end{abstract}

Keywords-COVID; distance learning; education; online learning; student; perception; preference

\section{INTRODUCTION}

Distance education is a provision of flexible opportunities due to which students can access formal learning from wherever they are. The three characteristics that define distance education are as follows: 1) the learning community is mostly in a separate space; 2) the process of instruction is assisted by two-way interaction between the instructors and students; 3) technology is used to facilitate learning and communication [1]. In the past decade, many universities worldwide started to offer distance learning programs and courses to reach students who find it difficult to pursue their studies due to constraints of time, geographical distance and commitments.

Various tools have been developed to digitalize educational resources as well as to enable instructors to meet and engage the learners virtually, such as the learning management system, digital books and so on [2]. Despite the increasing adoption of technology, some institutions have not yet implemented online distance learning as they are not prepared for an entirely webbased experience [3], [4]. Online learning is normally considered an alternative or complementary to physical classroom instruction for gaining knowledge and integrating technology [5], [3].

However, the emergence of the deadly coronavirus disease at the end of 2019, which gradually swept all over the globe, brought instant and dramatic changes in education. As a measure to control and minimize virus transmission, the governments in many countries around the world, including Malaysia, implemented mandatory closure of educational institutions and all their physical teaching and learning activities. In Malaysia, the disease started to emerge at the end of February 2020, and the lockdown was then imposed on the 18th of March, 2020, following the Movement Control Order (MCO) issued by the government. To ensure continuation of learning, academic institutions had no choice but to implement emergency remote education [6].

This abrupt paradigm shift from traditional brick-andmortar learning to completely internet-based instruction greatly impacted everyone involved, particularly the students who registered for face-to-face education in campus, but, all of a sudden, had to switch from the conventional style of learning that they desired and had been accustomed to. Further, those residing in rural areas or in a non-conducive environment face greater challenges to learning efficiently online [7]. Educators and learning institutions also encountered difficulties in adapting to the sudden change [6], [8]. For instance, lecturers have to tailor activities and assessments to the digital environment and also had to learn to use various technologyenhanced educational tools in a short span of time. Moreover, unstable or insufficient network also poses unprecedented challenges for both lecturers and students when conducting live video conferencing sessions [9].

School of Professional and Continuing Education (SPACE), a faculty of Universiti Teknologi Malaysia (UTM), had adopted Blackboard as their new learning management system before the COVID-19 pandemic. The adoption was still at the infant stage: Not everyone in the community utilized the system, and the basic training, which was also ongoing, primarily focused on the features of the technology that complement classroom education. When campus closure was enforced by the government, training for online learning using Blackboard was given to all lecturers and students, but lecturers were allowed to use any platform or tool they preferred or considered as a better fit for their course and their students' preference as long as the educational activities were

\footnotetext{
UTMSPACE Research Grant: Potential Development Fund SP-PDF2003
} 
conducted as per schedule and the learning outcomes were achieved. This flexibility was allowed to minimize the stress and disruption caused by the coronavirus outbreak.

Hence, during remote teaching, Blackboard was the official platform used by the majority of the lecturers in SPACE, UTM, followed by Google Classroom and other mediums for asynchronous activities that involved no real-time interaction. In terms of synchronous activities that required concurrent two-way communication between lecturers and students, the commonly used video conferencing platforms were Blackboard Collaborate, Google Meet, Cisco Webex and Zoom.

More than a year has passed, but the situation is still unstable, with the COVID-19 case numbers fluctuating and sometimes substantially rising. This has forced universities and faculties in Malaysia, including SPACE, to remain primarily closed. The ambiguous future demands that governments and learning institutes plan and implement a flexible and robust education system. Considering this and the momentous acceleration of digital learning due to the pandemic, it can be expected that the Internet will continue playing a significant role in human life. SPACE, for example, is currently preparing to develop Open and Distance Learning (ODL) programs and micro-credentials. Thus, evaluating the current adoption of remote learning as well as the students' experiences of and preference towards online education is critical for providing guidance to institutions and assisting them in deciding on, designing and implementing a relevant and fulfilling approach to education [9].

Therefore, the objectives of this research are to 1) determine students' perceptions of the online distance education conducted during the COVID-19 pandemic; 2) identify students' preference for online learning. Even though various aspects, such as challenges, implications and strategies, have been discussed and studied by many researchers [5], [10], [13], [25], most of them focused on a certain subject or presented a general view of the students' perception despite their diverse backgrounds. Hence, this research intends to enrich the current literature by providing the perspective of diploma students, which, to the best of the author's knowledge, has not yet been discussed. Most of the prior studies collected data mainly from postgraduate, degree and foundation students [10]. Furthermore, the findings on the difference of students' perception among gender, household income, prior e-learning experience and area of residence can be useful for institutions when planning the online teaching and learning activities. The following sections of this paper comprise of the literature review, methodology, results and discussion, followed by conclusion and future works.

\section{LITERATURE REVIEW}

\section{A. Students' Perceptions of Online Learning}

Investigations had been carried out in the form of numerous studies to determine students' perceptions and attitudes towards the completely digital education during the coronavirus outbreak, and one of the popular topics discussed was the challenges faced. For example, [11] found that the biggest concern among students in Jordanian medical schools was poor Internet coverage, followed by Internet data limitation, learning platform variation and insufficient devices. Similarly, the findings of another study showed that $69 \%$ of 762 students from two universities in Romania faced technical problems with the platform used by the university, whereas $14.8 \%$ had inadequate devices and mobile connection. Other challenges that the leaners had to cope with were mainly connected to the lecturers, such as limited employment of tools, lack of necessary skills and motivation to improve and adapt their teaching styles to the digital environment, provision of insufficient support for easing students' learning process as well as the giving of an excessive number of tasks and poor adherence to the learning schedule [12].

Another research summarized and divided the learning barriers encountered by 670 medical students into five categories: technological issues, individual issues (such as health and challenges to adjust to the learning style), domestic issues (such as a non-conducive environment and family and financial problems), institutional barriers and community barriers [13]. In the context of Malaysia, 147 students from 16 universities expressed issues related to administration, social interactions, technical problems, Internet connection, learning time, learning support and motivation [7]. Lack of interaction was also pointed out in another research [5], [10]. Generally, the results from these studies indicated that students encountered similar difficulties regardless of their nationality and background, but differences also existed.

On the positive side, students do acknowledge the advantages of e-learning, such as being able to continue their education remotely from the comfort of their homes, the usefulness of having recorded videos to facilitate their studying and revision process and the development of their self-directed learning skills [14]. Results from other literature showed comfortable learning environment as one of the most prevalent benefits of online education in addition to the flexibility of learning anytime and anywhere and the reduction of transportation time and expenses [5], [11]. For enhancing online learning, students suggested that the interaction be improved and the workload be reduced [14]. Nevertheless, some studies discovered the students' satisfaction with the elearning classroom interactions as well as their academic achievement during the pandemic [5].

\section{B. Students' Preference of Online Learning}

One of the frequently asked questions in past researches on learners' preference with regard to digital instruction was related to the mode of learning: Do learners favor a completely online, a completely face-to-face or a blended, hybrid approach? Blended was the most desired method according to multiple studies [15], [16], [17]. Although students approved of the benefit of learning flexibility that comes with online education, they were not keen on the idea of shifting entirely to the digital mode as they did not wish to lose the human aspect and the collaborative opportunities that come from physical interaction, which they believed were crucial for adapting to the workplace environment in the future [18].

The author in [24] showed that agriculture students were more inclined towards learning via smartphone followed by laptop compared to other devices and through recorded videos rather than live sessions or reading materials. In terms of class 
schedule and class duration, the findings revealed that learners wished to have 45-minute classes twice per week, with 15minute breaks between classes. The majority of the survey respondents indicated that they wanted the course material to be complemented with videos that have instructors explaining using whiteboard or PowerPoint. In terms of assessment, 76\% of them wished to have quizzes and assignments at the end of each class for effective learning and academic success. They also preferred to be given one week to submit assignments or assigned a due date that was before the next scheduled class session. The students stated that they liked attending online examinations, particularly if they had multiple-choice-question format [18].

\section{METHODOLOGY}

\section{A. Participants and the Scope of the Study}

This research was carried out in SPACE, a faculty of UTM, a higher education institution in Malaysia. From a population of 1347 full-time diploma students, those undergoing industrial internship were excluded, and 408 (30\%) students from all 18 diploma programs offered by the university participated in the survey. The students belonged to the engineering, management, computer science and services or geomatics and built environment departments. None of them had experienced online distance learning programs or courses before the pandemic. They are local students who had enrolled at the university expecting to receive formal education on campus, but since March 2020, they had to attend classes online from their homes due to the movement control order implemented by the Malaysian government. This study was conducted from the 27th of December, 2020, to the 10th of January, 2021; by this time, the students had experienced eight months of fully online learning. Blackboard was the main learning management system used by the students, and other applications such as WhatsApp, Google Classroom and many more were also used.

During data cleaning, 31 responses had to be removed for the Likert scale questions' quantitative analysis, leaving 377 (28\%) responses. The reason behind this elimination is explained in the next section, under data collection and analysis. Table I shows the demographic characteristics of the 377 respondents, which comprised of students from semesters one through six.

Overall, majority of the students live in urban areas (76.9\%), and used their home Wi-Fi to access the Internet for their e-learning activities during the pandemic (78.2\%). Almost $90 \%$ respondents had moderate-level information technology (IT) skills. As for the time spent every day for online learning, 237 (62.9\%) of them chose five to eight hours, which is the expected average daily learning time based on the students' learning schedules. Students' household income was classified into three categories: B40 for the low-income category (less than RM 4,849), M40 for the middle-income category (between RM 4,850 and RM 10,959) and T40 for the highincome category (RM 10,960 or more).

\section{B. Data Collection and Analysis}

This research employed a cross-sectional survey in which the data was collected at the same time [19]. Purposeful sampling strategy was opted for because the scope of this research was diploma students from the same university who had experienced online distance learning for the first time. The online questionnaire used for this study began with an introduction to brief the respondents about the purpose of the survey and assure them about their anonymity and the confidentiality of their responses. The questionnaire consisted of three main segments: demographic information, students' perception and students' preference, using multiple choice questions, Likert scale and open-ended questions developed based on relevant literature and modified to suit the context of this research.

The items used to measure satisfaction were adapted from [20], and the items for measuring online learning advantages and challenges were adapted from [18] and [21]. The survey questions were written in English as well as Bahasa Melayu to ensure that no language barrier problem occurred if any of the respondents did not understand the former language well. Since the respondents came from various programs of study in which their respective lecturers employed different tools, general questions were used for the survey; no questions were asked about specific subjects or learning platforms.

Once the questionnaire was developed in Google Forms, it was reviewed by an educational technology expert and assessed through a pilot test. The findings from the pilot test indicated good reliability of the Likert scale questions based on Cronbach's alpha values (0.854 for satisfaction, 0.881 for usefulness, 0.760 for challenges). Nonetheless, some amendments were done based on students' comments on questions that they found unclear and difficult to understand. The improved questionnaire was then sent to all respective heads of programs with the request to share it with their students via WhatsApp. This approach was selected to ensure that feedback was obtained for each program offered by the university. An e-gift voucher was emailed to them as a token of appreciation for supporting this research.

The collected data was then examined, first based on the five-point Likert scale questions to detect straight-lining and contradictory answers as they represent responses that were not carefully and thoughtfully given. Such responses need to be removed as they can reduce the validity of the quantitative study [22]. However, the feedbacks obtained for open-ended questions were all considered for analysis.

Once the data was screened, the quantitative results were analyzed using the SPSS software for descriptive and inferential statistics, including independent samples t-test, and Spearman's correlation analysis. On the other hand, the analysis of the open-ended feedbacks was based on the constant comparative method, which involves data coding followed by the categorization and comparison of data to identify the themes for similar responses and, finally, the calculation of the frequency for each theme [23].

\section{RESUltS AND DISCUSSION}

\section{A. Students' Perceptions of the Online Learning Conducted During the Coronavirus Pandemic}

The way students viewed the remote education conducted during the pandemic was studied under three categories. The 
first one was regarding their satisfaction, and the results from six Likert scale questions, as displayed in Table II, revealed not very impressive contentment among the respondents.

TABLE I. DEMOGRAPHIC CHARACTERISTICS OF 377 STUDENTS

\begin{tabular}{|c|c|c|c|}
\hline Characteristic & Category & $\mathbf{N}$ & Percentage \\
\hline \multirow{2}{*}{ Gender } & Male & 170 & $45.1 \%$ \\
\hline & Female & 207 & $54.9 \%$ \\
\hline \multirow{2}{*}{$\begin{array}{l}\text { Internet access used } \\
\text { for learning }\end{array}$} & Home Wi-Fi & 295 & $78.2 \%$ \\
\hline & Mobile hotspot & 179 & $47.5 \%$ \\
\hline \multirow{3}{*}{$\begin{array}{l}\text { Information } \\
\text { technology skills level }\end{array}$} & High & 22 & $5.8 \%$ \\
\hline & Moderate & 326 & $86.5 \%$ \\
\hline & Low & 29 & $7.7 \%$ \\
\hline \multirow{2}{*}{$\begin{array}{l}\text { Have prior online } \\
\text { learning experience }\end{array}$} & Yes & 65 & $17.2 \%$ \\
\hline & No & 312 & $82.8 \%$ \\
\hline \multirow{2}{*}{$\begin{array}{l}\text { Current area of } \\
\text { residence }\end{array}$} & Rural & 87 & $23.1 \%$ \\
\hline & Urban & 290 & $76.9 \%$ \\
\hline \multirow{4}{*}{$\begin{array}{l}\text { Daily hours spent on } \\
\text { e-learning }\end{array}$} & Less than 5 hours & 30 & $7.9 \%$ \\
\hline & 5 to 8 hours & 237 & $62.9 \%$ \\
\hline & 9 to 12 hours & 71 & $18.9 \%$ \\
\hline & More than 12 hours & 39 & $10.3 \%$ \\
\hline \multirow{3}{*}{$\begin{array}{l}\text { Household income } \\
\text { category }\end{array}$} & B40 (Low income) & 157 & $41.6 \%$ \\
\hline & M40 (Middle income) & 161 & $42.7 \%$ \\
\hline & T40 (High income) & 59 & $15.6 \%$ \\
\hline
\end{tabular}

TABLE II. DESCRIPTIVE STATISTICS FOR ONLINE LEARNING SATISFACTION

\begin{tabular}{|l|l|l|l|l|l|l|}
\hline Item & $\begin{array}{l}\text { SD } \\
\text { (\%) }\end{array}$ & $\begin{array}{l}\text { D } \\
\text { (\%) }\end{array}$ & $\begin{array}{l}\text { N } \\
\text { (\%) }\end{array}$ & $\begin{array}{l}\text { A } \\
\text { (\%) }\end{array}$ & $\begin{array}{l}\text { SA } \\
\text { (\%) }\end{array}$ & Mean \\
\hline $\begin{array}{l}\text { I am satisfied with } \\
\text { the online classes } \\
\text { conducted during } \\
\text { this pandemic }\end{array}$ & 8.5 & 16.4 & 36.3 & 30.0 & 8.8 & 3.14 \\
\hline $\begin{array}{l}\text { I am satisfied with } \\
\text { the online learning } \\
\text { materials provided } \\
\text { by lecturer }\end{array}$ & 3.2 & 9.3 & 28.4 & 43.5 & 15.6 & 3.59 \\
\hline $\begin{array}{l}\text { I am satisfied with } \\
\text { the online } \\
\text { assessments such as } \\
\text { assignment, quiz, } \\
\text { test and exam }\end{array}$ & 4.2 & 7.7 & 29.7 & 38.5 & 19.9 & 3.62 \\
\hline $\begin{array}{l}\text { I am satisfied with } \\
\text { lecturer's teaching } \\
\text { delivery through } \\
\text { online platform }\end{array}$ & 5.0 & 12.7 & 31.6 & 34.2 & 16.4 & 3.44 \\
\hline $\begin{array}{l}\text { I am satisfied with } \\
\text { the gained } \\
\text { knowledge and } \\
\text { skills }\end{array}$ & 5.8 & 12.2 & 34.0 & 35.8 & 12.2 & 3.36 \\
\hline $\begin{array}{l}\text { I am interested to } \\
\text { continue learning } \\
\text { through online } \\
\text { medium }\end{array}$ & 34.5 & 15.6 & 25.2 & 15.4 & 9.3 & 2.49 \\
\hline
\end{tabular}

SD: strongly disagree, D: disagree, N: not sure, A: agree, SA: strongly agree
The most negative outlook was observed in students' intention to continue learning through the online medium, with not more than a quarter of them showing interest, and the mean score for it was also the lowest compared to that for the other items. Previous researches received similar results: They showed that more than $60 \%$ of the respondents did not plan to continue using e-learning in the future [21], [24]. Another study revealed that students preferred the semester to be postponed and the digital education to be halted during the pandemic [25].

One of the factors that might have caused this discouraging emotion among students was probably the emergency implementation of distance learning, which went against their will, habit and expectation to learn on campus. This aspect is further explored in the next section, which is on the preference of students towards digital education.

For the first five items in the satisfaction category, the total percentage of students who agreed or strongly agreed was more than the percentage of those who showed disapproval, particularly for items two, three and four, with about half of the participants indicating their satisfaction with the learning materials, assessments and online platform. In order to understand the reasons behind the displeasure of the participants, the challenges encountered by the students were discussed and their e-learning experience was further explored in the next category of the questionnaire. It is interesting to note that another research that found positive satisfaction among respondents also obtained contradicting results for the intention to continue e-learning [23].

Given the sudden change from learning on campus to learning remotely, which may have caused distress among students, the participants were asked to rate the perceived usefulness of online education through 11 questions, as showcased in Table III, before being surveyed on the challenges and preferences. This was done to make them realize that this learning method also has its advantages. Overall, mixed results were observed: Based on the mean score, average feedbacks from students ranged from 2.77 to 4.11. The highest ones were not a surprise as the provision to access learning materials anytime from anywhere and re-watch recordings were widely acknowledged benefits of virtual instruction.

Apart from that, more participants agreed that digital learning is useful because they found it flexible, it did not require them to travel to attend lectures, the money spent was less than that spent when learning on campus, they felt comfortable attending online classes and learning online, they could improve their independent and technical skills and they were able to get help from lecturers, who also responded quickly. However, the opposite result was obtained for interaction: A slightly higher percentage of respondents found interacting virtually with lecturers and students uncomfortable. This finding is in line with the multiple studies that highlighted social interaction as one of the barriers to remote education; thus, this element needs to be looked into when designing online courses to improve the impression of students with regard to distance education and enhance their learning experience [5], [7], [10]. 
TABLE III. DESCRIPTIVE STATISTICS FOR STUDENTS’ PERCEPTION OF THE BENEFITS OF ONLINE LEARNING

\begin{tabular}{|l|l|l|l|l|l|l|}
\hline Item & $\begin{array}{l}\text { SD } \\
\text { (\%) }\end{array}$ & $\begin{array}{l}\text { D } \\
\text { (\%) }\end{array}$ & $\begin{array}{l}\text { N } \\
\text { (\%) }\end{array}$ & $\begin{array}{l}\text { A } \\
\text { (\%) }\end{array}$ & $\begin{array}{l}\text { SA } \\
\mathbf{( \% )}\end{array}$ & Mean \\
\hline $\begin{array}{l}\text { I do not need to } \\
\text { travel to campus to } \\
\text { attend online class }\end{array}$ & 15.1 & 9.0 & 20.4 & 23.3 & 32.1 & 3.48 \\
\hline $\begin{array}{l}\text { The expenses of } \\
\text { online learning are } \\
\text { less than those of } \\
\text { learning on campus }\end{array}$ & 5.8 & 7.7 & 23.9 & 28.1 & 34.5 & 3.78 \\
\hline $\begin{array}{l}\text { Online classes are } \\
\text { flexible }\end{array}$ & 8.2 & 9.5 & 36.1 & 27.9 & 18.3 & 3.38 \\
\hline $\begin{array}{l}\text { I can re-watch video } \\
\text { recording }\end{array}$ & 2.4 & 4.5 & 13.0 & 30.5 & 49.6 & 4.20 \\
\hline $\begin{array}{l}\text { I can access learning } \\
\text { materials anywhere } \\
\text { and anytime }\end{array}$ & 1.1 & 4.0 & 18.6 & 35.8 & 40.6 & 4.11 \\
\hline $\begin{array}{l}\text { It is comfortable to } \\
\text { attend online lectures } \\
\text { and learn online }\end{array}$ & 14.9 & 16.2 & 31.8 & 22.0 & 15.1 & 3.06 \\
\hline $\begin{array}{l}\text { It is comfortable to } \\
\text { interact with } \\
\text { lecturers through } \\
\text { online medium }\end{array}$ & 15.4 & 20.7 & 36.9 & 17.8 & 9.3 & 2.85 \\
\hline $\begin{array}{l}\text { It is comfortable to } \\
\text { interact with } \\
\text { classmates through } \\
\text { online medium }\end{array}$ & 20.7 & 20.2 & 31.3 & 17.5 & 10.3 & 2.77 \\
\hline $\begin{array}{l}\text { Online learning } \\
\text { allows me to learn to } \\
\text { be independent }\end{array}$ & 10.9 & 8.0 & 31.6 & 27.3 & 22.3 & 3.42 \\
\hline $\begin{array}{l}\text { Online learning } \\
\text { allows me to } \\
\text { improve my } \\
\text { technical skill in } \\
\text { using electronic } \\
\text { gadgets }\end{array}$ & 3.4 & 5.8 & 24.4 & 38.2 & 28.1 & 3.82 \\
\hline $\begin{array}{l}\text { I can ask lecturers } \\
\text { questions and receive } \\
\text { a quick response } \\
\text { through online } \\
\text { medium }\end{array}$ & 12.7 & 15.6 & 31.6 & 28.4 & 11.7 & 3.11 \\
\hline
\end{tabular}

Table IV summarizes the descriptive statistics for students' responses with regard to the challenges they experienced when learning remotely during the COVID-19 pandemic; this section comprised of eight questions. With regard to the first and second items, more than half of the respondents had difficulty interacting with their lecturers and classmates, proving the result obtained earlier. On the other hand, quite a neutral perception was displayed with regard to the problem of Internet connection, perhaps because nearly $80 \%$ respondents live in urban areas. A slightly higher percentage of participants struggled with poor learning conditions, lack of self-discipline and adjusting their style of learning compared with those who did not have problems with these.

The most prominent obstacles faced by students were difficulty in staying focused and lack of motivation. Therefore, instructors can try to conduct more engaging learning activities and think of ways to sustain the attention of students during lessons. Lecturers, academic advisors and counselors need to be more attentive and help boost students' motivation more often.
TABLE IV. DESCRIPTIVE STATISTICS For StUdENTS' PERCEPTION OF THE CHALLENGES OF ONLINE LEARNING

\begin{tabular}{|l|l|l|l|l|l|l|}
\hline Item & $\begin{array}{l}\text { SD } \\
\text { (\%) }\end{array}$ & $\begin{array}{l}\text { D } \\
\text { (\%) }\end{array}$ & $\begin{array}{l}\text { N } \\
\text { (\%) }\end{array}$ & $\begin{array}{l}\text { A } \\
\text { (\%) }\end{array}$ & $\begin{array}{l}\text { SA } \\
\text { (\%) }\end{array}$ & Mean \\
\hline $\begin{array}{l}\text { It is difficult to } \\
\text { interact with } \\
\text { lecturer through } \\
\text { online medium }\end{array}$ & 6.1 & 12.5 & 25.7 & 28.4 & 27.3 & 3.58 \\
\hline $\begin{array}{l}\text { It is difficult to } \\
\text { interact with } \\
\text { classmates through } \\
\text { online medium }\end{array}$ & 7.7 & 13.3 & 22.0 & 27.3 & 29.7 & 3.58 \\
\hline $\begin{array}{l}\text { I have poor, limited } \\
\text { and unstable } \\
\text { internet connection, } \\
\text { which affects my } \\
\text { online learning }\end{array}$ & 12.5 & 21.2 & 29.4 & 19.9 & 17.0 & 3.08 \\
\hline $\begin{array}{l}\text { I have poor } \\
\text { learning conditions } \\
\text { at home, which } \\
\text { affects my online } \\
\text { learning }\end{array}$ & 9.5 & 18.3 & 28.6 & 23.3 & 20.2 & 3.26 \\
\hline $\begin{array}{l}\text { I have lack of self- } \\
\text { discipline, which } \\
\text { affects my online } \\
\text { learning }\end{array}$ & 9.0 & 19.4 & 31.8 & 23.9 & 15.9 & 3.18 \\
\hline $\begin{array}{l}\text { It is difficult to } \\
\text { adjust my learning } \\
\text { style }\end{array}$ & 7.4 & 19.4 & 32.9 & 23.1 & 17.2 & 3.23 \\
\hline $\begin{array}{l}\text { It is difficult for me } \\
\text { to stay focused } \\
\text { during online } \\
\text { learning }\end{array}$ & 3.2 & 7.2 & 25.5 & 27.3 & 36.9 & 3.88 \\
\hline $\begin{array}{l}\text { I have less } \\
\text { motivation when } \\
\text { learning online } \\
\text { compared to face- } \\
\text { to-face learning }\end{array}$ & 3.7 & 8.0 & 24.1 & 29.2 & 35.0 & 3.84 \\
\hline
\end{tabular}

SD: strongly disagree, D: disagree, N: not sure, A: agree, SA: strongly agree

\section{B. Differences in Students' Perceptions based on Gender, Household Income, Online Learning Experience and Area of Residence}

According to the independent samples t-tests' results, there was no significant difference in the mean of satisfaction, perceived usefulness and challenges based on gender and household income. Nevertheless, students who had prior online learning experience had lower perceived challenges $(\mathrm{M}=3.22$, $\mathrm{SD}=0.98)$ than those who did not have experience $(\mathrm{M}=3.50$, $\mathrm{SD}=0.79), \mathrm{t}(82.542)=-2.161, \mathrm{p}=0.034$. The $\mathrm{t}$-test analysis for each item showed that the significant difference was in terms of the difficulty to adapt learning styles $t(375)=-3.157$, $\mathrm{p}=0.002$, as well as remain focused $\mathrm{t}(375)=3.738, \mathrm{p}=0.000$, and motivated $\mathrm{t}(82.979)=-3.028, \mathrm{p}=0.003$.

Students who lived in rural regions demonstrated substantial difference in their perceptions of the challenges during the emergency remote education $\mathrm{t}(375)=2.336, \mathrm{p}=$ 0.02 , specifically in terms of having poor learning conditions at home $\mathrm{t}(375)=4.195, \mathrm{p}=0.000$, in addition to poor, limited and unstable internet connection, which they felt were affecting their online learning $t(375)=3.515, p=0.000$. Nevertheless, there was not much difference in the overall satisfaction 
between respondents from rural areas and those from urban areas $\mathrm{t}(375)=0.595, \mathrm{p}=0.552$, and this gave the impression that the area of residence factor did not play a critical role in satisfying online learners. The finding of this study also reveals that participants' gender, digital learning experience, area of residence and whether their family have low income or not did not influence their perceptions of the advantages of online learning.

\section{Relatioship of Semester of Study, IT Level and Household Income with Students' Perceptions}

This research investigated the association of several factors with the perceptions of students using Spearman's correlation analysis. Respondents' semester of study exhibited statistically significant weak negative correlation with distance learning satisfaction (rho $=-0.255, \mathrm{p}=0.000$ ) and perceived usefulness (rho $=-0.212, \mathrm{p}=0.000$ ), and it exhibited a weak positive relation with the challenges encountered (rho $=0.207, \mathrm{p}=$ 0.000 ). This might be because students in the higher semesters need to learn more difficult subjects that require them to take up more hands-on and practical activities to gain a better understanding and develop relevant skills. Therefore, the limitations of remote learning might pose more difficulties and give more disappointment to them compared with students in lower semesters of study.

On the other hand, the associations of the IT level with satisfaction (rho $=0.057, \mathrm{p}=0.273$ ) and perceived usefulness (rho $=0.071, p=0.172$ ) were found to be insignificant. In contrast, there was a significant weak negative correlation between the IT level and the challenges faced by participants during the emergency remote education (rho $=-0.111, \mathrm{p}=$ 0.031), indicating that students with higher-level IT skills encountered less obstacles when learning through the online medium.

Prior independent samples t-tests results showed that students' family status (whether low income or not) produced insignificant difference in students' perceptions towards digital learning. This correlation analysis further proved that there was indeed no significant relation between household income (rho $=0.087, \mathrm{p}=0.092$ ) and satisfaction (rho $=0.087, \mathrm{p}=0.092$ ), perceived usefulness (rho $=0.065, \mathrm{p}=0.211$ ) or challenges experienced by students when learning remotely during the pandemic (rho $=-0.036, \mathrm{p}=0.483$ ).

\section{Students' Preference of Online Learning}

Students' preference towards technology-enhanced education was analyzed based on all 408 original responses. When the respondents were asked about their preferred future learning method, blended format, which is a combination of both online instruction and physical instruction, received the highest votes from the participants; 167 (40.9\%) respondents selected this approach, as illustrated in Fig. 1. This outcome, which is consistent with the discoveries in prior studies [15], [16], [26], demonstrated the learners' desire to have technology embedded into their learning experience and also retain faceto-face interaction. In contrast, a study that investigated the perspective of students from education programs found out that the respondents favored face-to-face courses over other types of learning courses [3].
As shown in Fig. 2, the students chose assessments as the most relevant activities to be conducted via the digital platform, particularly quiz, followed by test and assignment. Since their online assessments were basically conducted in an open-book format, students might have felt more relaxed and less stressful in this mode compared with the traditional assessment mode they were used to. A survey in a prior study also received similar results; $60 \%$ of the 307 participants revealed that they liked attending online examinations [18]. On the contrary, another study revealed that for medical and nursing students, tests and examinations were the least preferred activities, whereas lectures and discussion were more appropriate [16]. Hence, the preferences of students can be said to differ depending on the type of program or course they take.

For other activities, half of the students felt that discussion could be carried out via the online medium, whereas only $24 \%$ of them thought that a group project was viable. Given the advanced technology and the various communication tools present in this digital age, such as social media, discussion forums and live video conference platforms, it was not a surprise that students had no problem in conversing with their peers online. Nonetheless, that a low number of students approved of online group project was understandable, given the limitations to having productive and effective collaboration and team activities virtually.

As shown in Fig. 3, the most popular online educational material was, understandably, digital notes, with 78\% (319 out of 408 participants) choosing it. Video tutorial was the next most favored, being approved by almost 73\% respondents. This finding was consistent with a previous study in which $84 \%$ of 307 students wanted their reading material to be supplemented with video content [18]. Moreover, since these are also the two most prominent features of distance learning courses such as Massive Open Online Courses, this result was probable [27].

In terms of the elements that students thought could make digital education engaging, as demonstrated in Fig. 4, animation and game-based learning were the top two mostfavored components, followed by virtual reality activities and simulation. As engagement has been shown to have an impact on making learning easier for students and indirectly influence their attitude towards the acceptance of an online learning tool [27] instructors as well as online course designers and developers can incorporate the aforementioned elements to promote students' participation and enjoyment in learning.

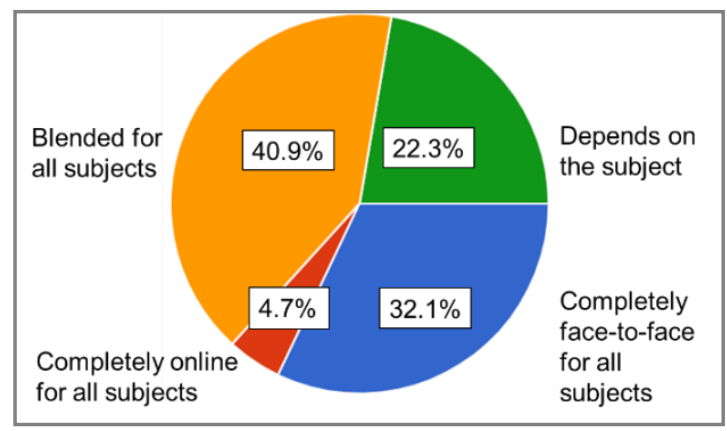

Fig. 1. Percentages for Students' Preferred Future Learning Methods ( $\mathrm{N}=$ 408). 


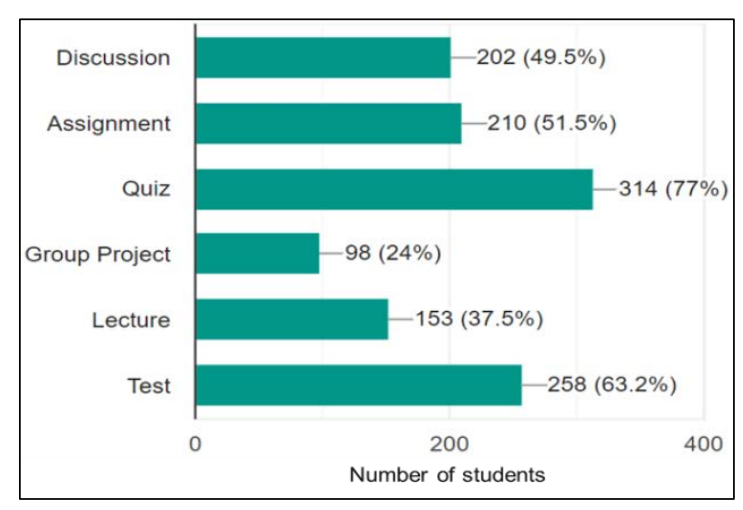

Fig. 2. Activities Recommended by Students as Suitable for Conducting online $(\mathrm{N}=408)$.

Since online education includes both synchronous and asynchronous activities, it is interesting to determine the preference of students regarding the delivery of lecture to support the reading materials. From the responses obtained as displayed in Fig. 5, more than half of the participants chose a combination of live video conferencing and pre-recorded video.

Both methods have their own advantages and limitations, for instance, live session allows real-time interaction but uses more internet data compared to other learning activities. On the other hand, pre-recorded videos provide the benefit for learners to receive and digest content in small chunks. Therefore, taking this feedback from students into consideration, educators can record several short videos for each chapter to let students go through before the live session which may just be spent on discussing certain parts that need further clarification.

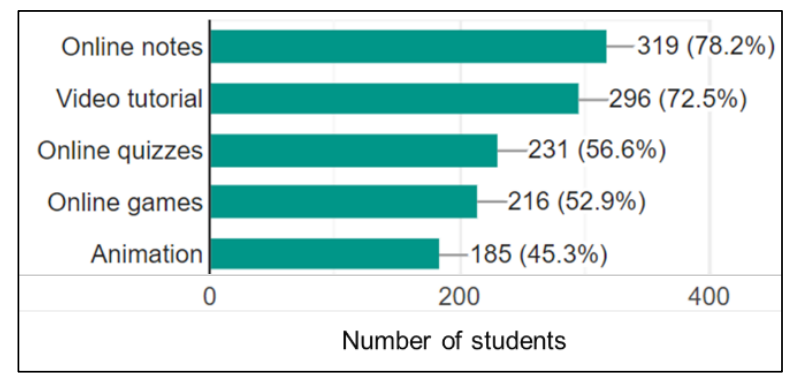

Fig. 3. Learning Materials that Students Preferred $(\mathrm{N}=408)$.

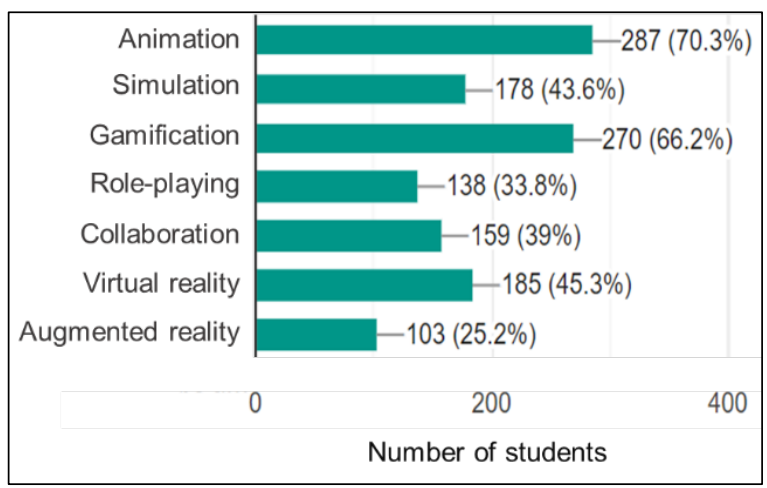

Fig. 4. Number of Students who Approved the Elements can make their elearning Engaging $(\mathrm{N}=408)$.

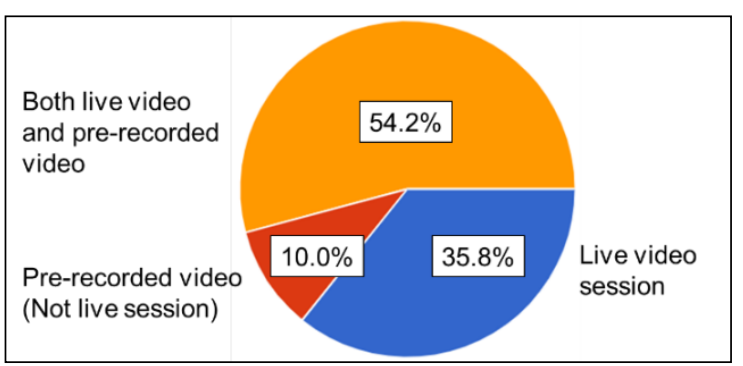

Fig. 5. Percentages of Students According to their Preferred Method (between Live Video and Pre-recorded Video).

The survey questionnaire also included an open-ended question asking for students' suggestions for improving their online learning. The responses were coded and classified into categories, as presented in Table $\mathrm{V}$, which include feedbacks that could be interpreted and found to be relevant to the question. The responses that were not counted mostly said that they (the respondent) had no suggestion and that everything was good.

Recommendations related to teaching style and learning activities were mostly about giving students short breaks between sessions and making classes fun and creative, for instance, through incorporation of online games or more interaction with students, so that they will not feel bored and sleepy. This is consistent with the findings displayed in Fig. 4, which shows that more than $60 \%$ students felt that game-based activities can make their learning attractive. Lecturers were suggested to conduct different kinds of activities in class, instead of just lecturing, to boost students' concentration, engagement and motivation.

Some of the respondents also emphasized that lecturers should give clear and thorough explanation using bilingual instruction, provide learning materials before the live session and respond quickly when needed. Apart from that, participants wanted instructors to enhance digital literacy and become more proficient at using the learning platforms as well as reduce group works due to the difficulty in discussing with teammates virtually.

TABLE V. FREQUENCY DISTRIBUTION OF THE SUGGESTIONS FOR IMPROVING ONLINE LEARNING AMONG 408 STUDENTS

\begin{tabular}{|l|l|l|}
\hline Suggestion category & N & Percentage \\
\hline Improve teaching style and learning activities & 71 & $17.4 \%$ \\
\hline Allow entry to campus & 63 & $15.4 \%$ \\
\hline Others & 20 & $4.9 \%$ \\
\hline Provide free, good and unlimited Internet access & 19 & $4.7 \%$ \\
\hline Improve learning materials or content & 18 & $4.4 \%$ \\
\hline Reduce workload & 11 & $2.7 \%$ \\
\hline Reduce live video session duration & 11 & $2.7 \%$ \\
\hline Implement hybrid or blended learning & 6 & $1.5 \%$ \\
\hline Use platform that consumes less data & 6 & $1.5 \%$ \\
\hline Provide longer assessment duration & 5 & $1.2 \%$ \\
\hline Pre-record short video lesson & 5 & $1.2 \%$ \\
\hline
\end{tabular}


Another very common response from students was regarding their desire to return to the campus. One respondent wrote, "I like to learn through physical class more as it is easier for me to ask questions and I can also understand faster." Another student stated that when they needed to learn at home, challenges such as family problems and family commitments hindered their learning. Other participants who expressed similar issues conveyed that since they needed to do household chores, they hoped that the lecturers could reduce the workload given to them.

Due to these problems, some participants suggested that the university should allow them to enter campus even if learning activities continued to be conducted online, so that they could focus better on their studies and work without disturbance. In contrast, other respondents stressed that remote learning be continued until there are no more COVID-19 cases; such feedbacks were included under the 'Others' category. The differences in students' opinions probably resulted from the dissimilar learning environments they had at their homes. Some participants also recommended hybrid instruction. One respondent said, "If can make it hybrid like physical learning for some days while the rest is online," and another student suggested the same for subjects that were difficult or required practical activities to be carried out on campus.

In terms of live sessions, one participant proposed, "Reduce the duration of learning to 40 minutes as the eyes become painful staring at the screen for too long." Another respondent shared, "It could be hard for us to stay focused and sit in one spot for a long period if the lecture is about two hours." In line with this, some students recommended that instructors prerecord short videos as they thought that these would be more useful and easier to refer to later compared with the recorded long-duration live video sessions. Moreover, respondents also wished that their lecturers prepared easy-to-understand, effective, comprehensive, complete and interesting learning material. Since online notes are the most desired educational material, as shown in Fig. 3, lecturers can enhance the quality of the notes they provide to students by following their suggestions.

\section{CONCLUSION}

The findings of this study showed that the satisfaction of the respondents was generally neutral to positive. Among the challenges encountered by them, the most common were connected with social interaction, concentration and motivation in learning. There was significant difference in the mean of the participants' perceived challenges based on their previous online learning experience. Blended format was revealed to be the most preferred learning method among respondents with animation and gamification receiving the highest vote for the elements that they believe can engage them.

Even though the research on the distance education during the coronavirus pandemic has rapidly grown, to the best of the authors' knowledge, the perspective of diploma program students has not yet been investigated. This research also evaluated the difference in students' perception based on their household income, area of residence, e-learning experience, semester of study and IT level. Hence, results from this study can enrich the existing literature on the learners' opinions on remote online learning. Furthermore, educational institutions, instructors as well as online course developers and designers can benefit from the findings of this research; they can understand the current situation, the attitudes of students towards digital instruction and their preferences and suggestions concerning this modern learning method. For instance, the majority of the students preferred a hybrid approach in which the content is delivered online through both live video sessions and pre-recorded videos. The most desired learning materials were online notes followed by video tutorials, quizzes, games and animation. Due to this pandemic, many institutions may have started planning for distance learning programs and courses. Therefore, the results presented in this study can assist them in designing and developing courses that can fulfill the needs and expectations of the students.

Since the findings of this study were obtained from diploma program students in a particular university, the results are relevant for similar cases but cannot be generalized to represent all higher education students. Future research may seek to include students from various institutions and program of study and evaluate the perception among them. The factors that influence learners' satisfaction towards distance education can also be investigated to assist in the continuous quality improvement of this learning method.

\section{ACKNOWLEDGMENT}

Authors thank UTMSPACE for the research opportunity under UTMSPACE Research Grant: Potential Development Fund SP-PDF2003 as well as Rozana Ismail, Erni Syuhada Mazwil Ishan, Chin Wei Bing, Nur Anis Syakira Awang and Puteri Sofia Mohd Noor for their assistance during the data collection and analysis.

\section{REFERENCES}

[1] B. D. M. Casey, "The historical development of distance education through technology," TechTrends: Linking Research and Practice to Improve Learning, vol. 52, no. 2, pp. 45-51, Apr. 2008. DOI: 10.1007/s11528-008-0135-z, [Online].

[2] F. Martin, B. Stamper, and C. Flowers, "Examining student perception of readiness for online learning: Importance and confidence," Online Learn. J., vol. 24, no. 2, pp. 38-58, 2020. DOI: 10.24059/olj.v24i2.2053, [Online].

[3] C. Coman, L.G. Țîru, L. Meseșan-Schmitz, C. Stanciu, and M. C. Bularca, "Online teaching and learning in higher education during the coronavirus pandemic: Students' perspective," Sustainability (Switzerland), vol. 12, no. 24, pp. 1-22, 2020. DOI: 10.3390/su122410367, [Online].

[4] K. Thompson and J. M. Lodge, "2020 vision: What happens next in education technology research in Australia," Australas. J. Educ. Technol., vol. 36, no. 4, pp. 1-8, 2020. DOI: 10.14742/ajet.6593, [Online].

[5] N. Arifiati, E. Nurkhayati, E. Nurdiawati, G. Pamungkas, S. Adha, A. Purwanto, O. Julyanto, and E. Azizi, "University students online learning system during Covid-19 pandemic: Advantages, constraints and solutions," Sys. Rev. Pharm., vol. 11, no. 7, pp. 570-576., 2020 [Online]. Available: http://www.sysrevpharm.org/?mno=9626.

[6] L. M. Hasani, H. R. Adnan, D. I. Sensuse, Kautsarina, and R. R. Suryono, "Factors affecting student's perceived readiness on abrupt distance learning adoption: Indonesian higher-education perspectives," 2020, pp. 286-292. DOI: 10.1109/ic2ie50715.2020.9274640.

[7] A. Ilias, N. Baidi, E. K. Ghani, and F. M. Razali, "Issues on the use of online learning: An exploratory study among university students during 
the COVID-19 pandemic," Univers. J. Educ. Res., vol. 8, no. 11, pp. 5092-5105, 2020. DOI: 10.13189/ujer.2020.081109, [Online].

[8] F. Alturise, "Difficulties in teaching online with blackboard learn effects of the COVID-19 pandemic in the western branch colleges of Qassim University,” Int. J. Adv. Comput. Sci. Appl., vol. 11, no. 5, pp. 74-81, 2020, doi: 10.14569/IJACSA.2020.0110512.

[9] J. K. M. Sia and A. Abbas Adamu, "Facing the unknown: Pandemic and higher education in Malaysia," Asian Educ. Dev. Stud., vol. ahead-ofprint, no. ahead-of-print, 2020. DOI: 10.1108/AEDS-05-2020-0114, [Online].

[10] A. A. Kamal, N. M. Shaipullah, L. Truna, M. Sabri, and S. N. Junaini, "Transitioning to online learning during COVID-19 Pandemic: Case study of a Pre-University Centre in Malaysia," Int. J. Adv. Comput. Sci. Appl., vol. 11, no. 6, pp. 217-223, 2020, doi: 10.14569/IJACSA.2020.0110628.

[11] M. Al-Balas, H. I. Al-Balas, H. M. Jaber, K. Obeidat, H. Al-Balas, E. A. Aborajooh, R. Al-Taher, and B. Al-Balas, "Distance learning in clinical medical education amid COVID-19 pandemic in Jordan: Current situation, challenges, and perspectives," BMC Med. Educ., vol. 20, no. 1, pp. 1-7, 2020. DOI: 10.1186/s12909-020-02428-3, [Online].

[12] R. E. Baticulon, N. R. I. Alberto, M. B. C. Baron, R. E. C. Mabulay, L. G. T. Rizada, J. J. Sy, C. J. S. Tiu, C. A. Clarion, and J. C. B. Reyes, "Barriers to online learning in the time of COVID-19: A national survey of medical students in the Philippines," MedRxiv, pp. 1-19, 2020. DOI: 10.1101/2020.07.16.20155747, preprint.

[13] K. Mukhtar, K. Javed, M. Arooj, and A Sethi, "Advantages, limitations and recommendations for online learning during COVID-19 pandemic era," Pak. J. Med. Sci., vol. 36, no. COVID19-S4, pp. S27-S31, 2020. DOI: 10.12669/pjms.36.COVID19-S4.2785, [Online].

[14] A. Farooq, A. Hakkala, S. Virtanen, and J. Isoaho, "Cybersecurity education and skills: Exploring students' perceptions, preferences and performance in a blended learning initiative," in IEEE EDUCON, Porto, Portugal, $2020, \quad$ pp. 1361-1369. DOI: 10.1109/EDUCON45650.2020.9125213.

[15] O. Imas, V. Kaminskaya, and A. Sherstneva, "Teaching math through blended learning," 2018. DOI: 10.1109/ICL.2015.7318081.

[16] R. Olum, L. Atulinda, E. Kigozi, D. R. Nassozi, A. Mulekwa, F. Bongomin, and S. Kiguli, "Medical education and e-learning during COVID-19 pandemic: Awareness, attitudes, preferences, and barriers among undergraduate medicine and nursing students at Makerere University, Uganda," J. Med. Educ. Curric. Dev., vol. 7, 238212052097321, 2020. DOI: 10.1177/2382120520973212, [Online].

[17] Y. E. V. Hong and L. Gardner, "An evaluation of blended courses: Reflections from undergraduates," 2019. Available:
https://aisel.aisnet.org/pacis2019/174?utm_source=aisel.aisnet.org\%2Fp acis2019\%2F174\&utm_medium=PDF\&utm_campaign=PDFCoverPage S.

[18] M. T, A. S, K. S. Aditya, and G. K. Jha, "Students' perception and preference for online education in India during COVID -19 pandemic," SSRN Electron. J., vol. 3, no. 1, p. 100101, 2020. DOI: 0.2139/ssrn.3596056, [Online].

[19] J. W. Creswell, Research Design: Qualitative, Quantitative, and Mixed Methods Approaches, Thousand Oak, CA: SAGE Publications, 2008, ch. 8, sec. 2 , pp. 146.

[20] T. Chen, L. Peng, X. Yin, J. Rong, J. Yang, and G. Cong, "Analysis of user satisfaction with online education platforms in China during the COVID-19 pandemic," Healthc., vol. 8, no. 3, p. 200, 2020. DOI: 10.3390/healthcare8030200, [Online].

[21] A. M. Sindiani, N. Obeidat, E. Alshdaifat, L. Elsalem, M. M. Alwani, H. Rawashdeh, A. S. Fares, T. Alalawne, and L. I. Tawalbeh, "Distance education during the COVID-19 outbreak: A cross-sectional study among medical students in North of Jordan," Ann. Med. Surg., vol. 59, no. August, pp. 186-194, 2020. DOI: 10.1016/j.amsu.2020.09.036, [Online].

[22] F. Brühlmann, S. Petralito, L. F. Aeschbach, and K. Opwis, "The quality of data collected online: An investigation of careless responding in a crowdsourced sample," Methods in Psychology, vol. 2, Nov. 2020. DOI: 10.1016/j.metip.2020.100022, [Online].

[23] B. G. Glaser, "The constant comparative method of qualitative analysis," Soc. Probl., vol. 12, no. 4, pp. 436-445, 1965. DOI: 10.2307/798843, [Online].

[24] E. Chung and V. N. Mathew, "Satisfied with online learning amidst COVID-19, but do you intend to continue using it?" Int. J. Acad. Res. Progress. Educ. Dev., vol. 9, no. 4, pp. 67-77, 2020. DOI: 10.6007/ijarped/v9-i4/8177, [Online].

[25] E. Aboagye, J. A. Yawson, and K. N. Appiah, "COVID-19 and elearning: The challenges of students in tertiary institutions," Soc. Educ. Res., vol. 2, no. 1, pp. 109-115, 2020. DOI: 10.37256/ser.122020422.

[26] H. H. R. Azami and R. Ibrahim, "Development and evaluation of massive open online course (MOOC) as a supplementary learning tool: An initial study," Int. J. Adv. Comput. Sci. Appl., vol. 10, no. 7, pp. 532537, 2019. DOI: 10.14569/ijacsa.2019.0100773, [Online].

[27] H. H. Razami and R. Ibrahim, "Investigating the factors that influence the acceptance of MOOC as a supplementary learning tool in higher education," Journal of Advanced Research in Dynamical and Control Systems, vol. 12, no. 3, pp. 522-530, 2020. DOI: 10.5373/JARDCS/V12I3/20201219, [Online]. 